\title{
Presentación
}

\section{El agua en la encrucijada climática: apropiaciones desiguales e injustas, riesgos de desastre y conflictos ambientales}

\section{(1) Diego Ríos}

Universidad de Buenos Aires. Facultad de Filosofía y Letras. Instituto de Geografía "Romualdo Ardissone". Programa de Investigaciones en Recursos Naturales y Ambiente (PIRNA). Buenos Aires, Argentina.

CONICET. Buenos Aires, Argentina.

\section{Constanza Riera}

Universidad de Buenos Aires. Facultad de Filosofía y Letras. Instituto de Geografía "Romualdo Ardissone". Programa de Investigaciones en Recursos Naturales y Ambiente (PIRNA). Buenos Aires, Argentina.

CONICET. Buenos Aires, Argentina.

\section{Anabel Calvo}

Universidad de Buenos Aires. Facultad de Filosofía y Letras. Instituto de Geografía "Romualdo Ardissone". Programa de Investigaciones en Recursos Naturales y Ambiente (PIRNA). Buenos Aires, Argentina.

Inundaciones, sequías, incendios o nevadas intensas son solo algunas de las manifestaciones disruptivas vinculadas a los extremos del agua con las que las sociedades han tenido que coexistir en distintos contextos espaciotemporales. La geografía y otras ciencias sociales que abordan procesos territoriales aportan marcos interpretativos para analizar las articulaciones complejas y contradictorias entre las sociedades, sus expresiones materiales y los riesgos ambientales. Lxs integrantes del Programa de Investigaciones en Recursos Naturales y Ambiente (PIRNA), perteneciente al Instituto de Geografía "Romualdo Ardissone" (Facultad de Filosofía y Letras, Universidad de Buenos Aires), vienen realizando aportes sobre estos tópicos.

Si bien entre 1960 y 1980 las preocupaciones vinculadas a los problemas ambientales aparecieron en las agendas de discusión de los organismos internacionales de cooperación, durante las últimas décadas el agua y sus extremos han encontrado un nuevo impulso con el surgimiento de la cuestión del Cambio Climático (CC) y su consolidación como la principal problemática ambiental a escala global. El presente Dossier retoma justamente estas problemáticas como tema central, presentando análisis de coyunturas particulares donde los usos del agua se encuentran en tensión. Una tensión que no sólo es producto de la variabilidad climática y sus extremos, sino que además su génesis responde a configuraciones sociales y políticas donde la apropiación desigual e injusta adquiere un papel central.

Reconocer esta génesis permite encuadrar a la cuestión del CC en su dimensión política, marcando una ruptura crítica con el discurso hegemónico de los organismos 
internacionales de cooperación especializados, tal es el caso del Intergovernmental Panel of Climate Change (IPCC). En efecto, en sus documentos sobre el CC aparecen recurrentemente nociones como adaptación, resiliencia y mitigación con las que se homologan los sistemas sociales a los sistemas naturales, y donde el CC termina concibiéndose como un problema físico a resolver.

Las nociones de resiliencia y adaptación reemplazan en el marco interpretativo a la vulnerabilidad social y se construyen semánticamente como términos ostensiblemente más despolitizados. Ello favorece la construcción de opacidades sobre los procesos socioespaciales injustos y desiguales, decisivos en la configuración de las condiciones de riesgos de desastre. Sin embargo, desde el punto de vista que aquí se presenta, se considera que son los procesos históricos de producción y acumulación los que al producir condiciones de vulnerabilidad generan espacios de riesgo en áreas rurales y urbanas sujetas a eventos hidrometeorológicos extremos. Si bien está claro que estos procesos son preexistentes al CC global actual, es necesario reconocer que este último no hará otra cosa que amplificarlos. La expansión de la frontera agropecuaria, la explotación de recursos naturales y la acumulación por despojo de los bienes comunes, la pauperización de amplios sectores de la sociedad, entre otros fenómenos/procesos, agudizan las causas y consecuencias del CC. Sin embargo, estas se tornan evidentes cuando los eventos hidrometeorológicos extremos se expresan en desastres.

El CC plantea la discusión ambiental en un doble juego de despolitización/politización. Por un lado, conduce a la despolitización de los procesos de vulnerabilización de amplias franjas de la sociedad -y la conflictividad que encierran- cuando se coloca el peso de las soluciones en respuestas técnicas que implican medidas físicas. Así, por ejemplo, para el IPCC la disminución de los Gases de Efecto Invernadero (GEI) es el objetivo indiscutible para restablecer las condiciones fisicoquímicas de la atmósfera y mitigar los efectos del CC. Por otro lado, la emergencia de nuevos movimientos sociales, a raíz de la multiplicación de los conflictos ambientales, recupera la cuestión del CC para argumentar sobre la necesidad de llevar adelante formas de producción sustentables. En este sentido, el CC se convierte en un activo político que fundamenta la crítica a los modelos de desarrollo vigentes.

La intensificación de los extremos hidrometeorológicos que informan los organismos internacionales en sus reportes hace emerger cada vez con mayor magnitud los conflictos. En el análisis de estos documentos se mencionan en forma difusa los intereses de los actores sociales que participan en las disputas por los bienes y servicios ambientales, desconociendo la racionalidad de los sujetos sociales en sus lógicas productivas. Así, los conflictos por el agua se agudizan con el CC y ponen de manifiesto el resultado del desarrollo desigual de las sociedades y sus territorios.

Las políticas públicas a las que se refieren los artículos del Dossier dan cuenta de diferentes respuestas de las instituciones estatales argentinas con relación al agua, al tiempo que ponen de manifiesto algunas de sus propias dificultades asociadas a la resolución de problemas que se reconocen como colectivos al abordarse desde la política. Los lineamientos de estas políticas muestran controversias en su aplicación y se relacionan con soluciones "tecnocráticas" vinculadas con: la infraestructura para el aprovisionamiento de agua; la retención y defensa ante épocas de sequía/inundaciones, con una mirada ingenieril a través de obras hidráulicas; la conservación de ecosistemas 
estratégicos como los humedales bajo la figura de Áreas Protegidas; la creación de instituciones ad hoc para planificar el manejo de cuencas hidrográficas, o la presencia de legislación ambiental que se pone en discusión a partir de los avances de determinadas actividades alentadas por el propio Estado. Las controversias sociales generadas con la implementación de estas medidas manifiestan la dificultad de llevar a cabo políticas públicas que permitan superar las injusticias hídricas y ambientales.

La imagen de la portada del Dossier pertenece al dibujante/caricaturista uruguayo, Leslie Ricciardi. Con Mitad y Mitad, título de la viñeta, el autor nos remite a la imagen icónica de la fotografía de la Tierra (The Blue Marble/ la canica azul) tomada desde el espacio a comienzos de los años setenta, pero esta vez bajo una interpretación en clave de parodia catastrofista. Nos muestra con ella la creciente preocupación acerca de la principal problemática ambiental en la agenda social a escala global de los últimos tiempos: el Cambio Climático.

En la imagen que encarna esta viñeta está representada la problemática ambiental de los extremos hidrometeorológicos, que aquí se aborda como parte de las discusiones críticas acerca del CC. Precisamente, el artículo que abre el Dossier, bajo autoría de Erik Swyngedouw, abona a ese campo y al marco de referencia de las cuestiones planteadas en esta presentación. ${ }^{1} \mathrm{El}$ autor advierte que el discurso del "deber ser" (posverdad) ambientalista, hegemonizado bajo la preocupación por el CC, en realidad no se enfoca en el problema climático per se, sino en sostener el modelo económico imperante. Ello, sin cuestionar al capitalismo, especialmente, en cuanto a la aceleración de las consecuencias ambientales adversas producidas en la etapa de la globalización neoliberal. En este sentido, el dióxido de carbono es un síntoma fetichizado, eje de la preocupación ambiental, que neutraliza los "procesos socio-ecológicos Reales" causantes del CC a través de un debate apolítico. Procesos vinculados con las "relaciones de poder socioecológico", en el marco de la acumulación del capital.

Como corolario, desde esta perspectiva se homogeniza a la sociedad en la abstracción de un "todxs amenazadxs", víctimas de una "naturaleza vengativa" que demanda de una acción conjunta. Esa idea de homogeneidad social, de "humanidad global", que aparece en los discursos sobre el clima, es un imaginario que encubre que al interior de la sociedad existen tensiones y antagonismos de clase que generan conflictos. Son los diferentes intereses en juego dados por las relaciones desiguales de poder los que otorgan sentido a la dimensión política, en este caso, en clave ambiental.

Las causas del problema ambiental, por otra parte, permanecen concebidas como externas a las relaciones socio-ecológicas propias del sistema. Suponer un consenso social "despolitizante" con relación al problema del CC, implica sostener el estatus quo desde el supuesto de que es el propio capitalismo quien podrá resolver y mejorar las condiciones climáticas y así evitar la catástrofe. Desde esta perspectiva, las políticas públicas sobre el particular quedan vacías de contenido al no estar articuladas con programas/planes que signifiquen transformaciones socio-ecológicas orientadas a un cambio profundo de las relaciones que estas implican.

1 Sobre este trabajo, en la sección Diálogos Punto Sur de este mismo número, se introduce el comentario de Andrés Núñez: Cambio climático y apocalipsis. Una mirada desde la geografía cultural a partir de un texto del geógrafo Erik Swyngedouw. 
Los cuatro artículos que siguen abordan casos de estudio en los que se presentan formas injustas y desiguales de apropiación y de uso del agua, así como sus manifestaciones extremas en el contexto del CC. Tal como aparecen representados los extremos hidrometeorológicos en las dos mitades de la Tierra en la viñeta de Leslie Ricciardi, los dos primeros artículos refieren al manejo de las aguas en áreas inundables de la Región Metropolitana de Buenos Aires (RMBA), mientras que el par restante remite a las formas controversiales de aprovechamiento del agua en provincias ubicadas en la llamada "diagonal árida argentina" (San Juan y Mendoza), sumidas en contextos de una mega-sequía.

El artículo de Gabriela Merlinsky y Melina Tobías incursiona en torno a los conflictos ambientales relacionados con el agua a partir del análisis sobre cómo se manifiestan las desigualdades para el acceso a los servicios de agua potable y saneamiento, y el riesgo frente a inundaciones en el espacio urbano. Las autoras utilizan el concepto de territorios hidrosociales para integrar las condiciones naturales con los procesos sociales de las cuencas metropolitanas de los ríos Matanza-Riachuelo y Reconquista, y así plantear que la circulación del agua tiene que ver con "flujos de poder" relacionados con procesos de valorización social. En estos territorios se manifiestan prácticas materiales y simbólicas con características particulares, que se vienen gestando a lo largo del tiempo con relación a la producción, apropiación y circulación del agua.

Las autoras señalan que, frente a los conflictos generados en estas cuencas, el enfoque de las políticas públicas aplicadas da cuenta de acciones diferenciales relacionadas con aspectos tales como las características de los actores sociales involucrados, los reclamos en la Justicia de los actores colectivos, la presencia/ausencia de organismos del Estado de diferente escala jurisdiccional o la creación de nuevas instituciones. Todos estos factores confluyen en conflictos hídricos relacionados a la distribución y a la circulación. Son las situaciones de exclusión y de desigualdad hídrica las que llevan a diferentes actores sociales a desarrollar estrategias de acción colectiva para plantear sus reclamos. De este modo, la demanda por una mayor "justicia hídrica" y por el acceso al agua como derecho se cristaliza en la disputa por el derecho a la ciudad.

Por su parte, Diego Ríos y Sergio Caruso proponen una mirada complementaria sobre la problemática de las áreas inundables/humedales pertenecientes a la RMBA. En su artículo analizan el reposicionamiento que han tenido las "tierras de agua" en los últimos tiempos, a partir de la interrelación entre diferentes procesos/dimensiones. Por un lado, revisan la construcción de distintos imaginarios geográficos sobre estas áreas; por otro, dan cuenta del surgimiento de conflictos ambientales de acuerdo con usos, destinos urbanos, valoraciones e intereses contrapuestos, y, por último, estudian las políticas públicas tendientes a la conservación y la utilización de los servicios ambientales para afrontar el CC.

A partir de la década de los noventa, las áreas inundables de la región pasaron a convertirse en un territorio en disputa por parte de distintos actores sociales, tanto en términos materiales como simbólicos. El desarrollo científico permitió que se avanzara en un mayor conocimiento sobre los humedales, destacando los servicios ambientales que brindan a la sociedad. Los nuevos sentidos sirvieron para revertir los imaginarios geográficos preexistentes de fuerte valoración negativa. Al tiempo que se intensificó la ocupación de esas áreas inundables por parte de los grupos más marginalizados (sus 
“ocupantes históricos”), también comenzaron a ser valorizadas por el submercado inmobiliario de las urbanizaciones cerradas destinadas a los grupos más acomodados, convirtiéndolas en meros recursos paisajísticos escenográficos. Esas profundas mutaciones generaron consecuencias ambientales adversas, que afectaron en forma desigual a los diferentes actores sociales, activando conflictos ambientales en los que las organizaciones sociales de base y ambientalistas ocuparon papeles protagónicos.

Por otro lado, desde una mirada de la historia ambiental y la ecología política, Facundo Rojas propone una periodización para abordar los usos del agua en San Juan y poner en discusión los imaginarios relacionados con las sequías e inundaciones, definidos de acuerdo con diferentes sectores sociales, actividades y territorios. Esta periodización tiene en cuenta los ciclos hidrosociales determinados en función de la información hidroclimática y las actividades productivas predominantes en el territorio. A medida que se intensifica el uso del agua para estas actividades, se instala la idea de aridez y escasez del recurso. De esta manera, las obras de infraestructura para riego se transforman en un aspecto central para disminuir el riesgo de sequía. El aumento del uso del agua, acompañado en los últimos años de una gran escasez de precipitaciones, genera conflictos y la presencia, cada vez de mayor peso, de movimientos socioambientales que reclaman por los efectos que producen las actividades extractivas desarrolladas en la región.

En el último de los artículos que integran este Dossier, Lucrecia Wagner plantea las controversias socioambientales que surgen en la provincia de Mendoza a partir de la explotación de petróleo en el yacimiento Vaca Muerta con técnicas de fracking que, en el contexto de gran sequía que atraviesa la región, amplifica el riesgo ambiental por la falta de información sobre el desarrollo de esta actividad. La autora utiliza el concepto de incertidumbre como dimensión del riesgo, para indicar las posibles consecuencias que pueden producirse debido a la falta de gestión del Estado de este conflicto ambiental. En línea con este concepto, señala que las propuestas de explotación, tanto desde el gobierno nacional como el provincial, van de la mano con la idea de generar nuevas "oportunidades" para el desarrollo de la región, planteando el inicio de este tipo de actividad sin los estudios suficientes y flexibilizando la legislación ambiental para responder a la demanda empresarial.

De esta manera, la dimensión política del CC y de las controversias en torno al aprovechamiento del agua se ponen en evidencia en los cuatro estudios de caso que integran el Dossier. Como muestra la imagen de la portada, desde el espacio se observa una mitad del planeta totalmente bajo las aguas, mientras que la otra mitad se quema bajo el fuego de descontroladas llamaradas: los extremos del agua pintan escenarios de desequilibrio y desastre, que no son sino otra cara de la desigualdad. Y en este escenario de "futuros distópicos" opuestos, no hay solución técnica que apague la llamas ni drene las inundaciones. La solución es política, como el problema lo es. Es por eso que los extremos del agua, como la problemática ambiental en general, son arena de conflictos donde se expresan los movimientos sociales que luchan por apropiaciones más justas del espacio y de sus recursos, o lo que es lo mismo, por mejores condiciones de vida. En esta perspectiva, el CC, signo indiscutido de la problemática ambiental global contemporánea, emerge como un potente dispositivo discursivo en la lucha política. 